Proceedings of the 43rd "Jaszowiec", International School and Conference on the Physics of Semiconductors, Wisła 2014

\title{
CdSe/ZnCdSe Quantum Dot Heterostructures for Yellow Spectral Range Grown on GaAs Substrates by Molecular Beam Epitaxy
}

\author{
S.V. Gronin ${ }^{a}$, S.V. Sorokin ${ }^{a}$, D.R. Kazanovi, ${ }^{a, b}$ I.V. Sedova ${ }^{a}$, G.V. KLimko ${ }^{a}$, \\ E.A. EvropeytSEV ${ }^{a}$, S.V. IVANOV ${ }^{a}$ \\ ${ }^{a}$ Ioffe Physical-Technical Institute of RAS, St.-Petersburg, Russia \\ ${ }^{b}$ St.Petersburg State Polytechnical University, St.-Petersburg, Russia
}

\begin{abstract}
This paper reports on theoretical calculations and fabrication by molecular beam epitaxy of wide-gap II-VI heterostructures emitting in the "true" yellow range $(560-600 \mathrm{~nm})$ at room temperature. The active region of the structures comprises CdSe quantum dot active layer embedded into a strained $\mathrm{Zn}_{1-x} \mathrm{Cd}_{x} \mathrm{Se}(x=0.2-0.5)$ quantum well surrounded by a $\mathrm{Zn}(\mathrm{S}, \mathrm{Se}) / \mathrm{ZnSe}$ superlattice. Calculations of the CdSe/(Zn, Cd)Se/Zn(S,Se) quantum dotquantum well luminescence wavelength performed using the envelope-function approximation predict rather narrow range of the total $\mathrm{Zn}_{1-x} \mathrm{Cd}_{x}$ Se quantum well thicknesses $(d \approx 2-4 \mathrm{~nm})$ reducing efficiently the emission wavelength, while the variation of $x(0.2-0.5)$ has much stronger effect. The calculations are in a reasonable agreement with the experimental data obtained on a series of test heterostructures. The maximum experimentally achieved emission wavelength at $300 \mathrm{~K}$ is as high as $600 \mathrm{~nm}$, while the intense room temperature photoluminescence has been observed up to $\lambda=590 \mathrm{~nm}$ only. To keep the structure pseudomorphic to GaAs as a whole the tensile-strained surrounding $\mathrm{ZnS}_{0.17} \mathrm{Se}_{0.83} / \mathrm{ZnSe}$ superlattice were introduced to compensate the compressive stress induced by the $\mathrm{Zn}_{1-x} \mathrm{Cd}_{x} \mathrm{Se}$ quantum well. The graded-index waveguide laser heterostructure with a $\mathrm{CdSe} / \mathrm{Zn}_{0.65} \mathrm{Cd}_{0.35} \mathrm{Se} / \mathrm{Zn}(\mathrm{S}, \mathrm{Se})$ quantum dot-quantum well active region emitting at $\lambda=576 \mathrm{~nm}(T=300 \mathrm{~K})$ with the 77 to $300 \mathrm{~K}$ intensity ratio of 2.5 has been demonstrated.
\end{abstract}

DOI: 10.12693/APhysPolA.126.1096

PACS: 81.15.Hi, 78.55.Et, 78.67.Hc, 68.65.Fg

\section{Introduction}

II-VI wide-gap semiconductor heterostructures still attract great attention due to prospects of using in optoelectronic devices emitting in green and yellow-green ranges of visible spectrum. Different approaches were employed to extend the laser wavelength of II-VI heterostructures lattice-mathced to GaAs to the "true" yellow $(\lambda=570-600 \mathrm{~nm})$ range, which is of importance for expanding the color space (CMYK) in the printing and projection devices. Among them laser diodes (LDs) with ZnCdSSe $(\lambda=560 \mathrm{~nm})[1]$ and BeZnCdSe $(\lambda=570 \mathrm{~nm})[2]$ strained quantum wells $(\mathrm{QW})$, as well as a micro-chip LD converter comprising a CdSe/ZnSe quantum dot (QD) laser structure with CdSe nominal thickness enhanced beyond 3.1 monolayer (ML) $(\lambda=$ $567 \mathrm{~nm}$ ) [3]. However, the latter demonstrated reduced luminescence efficiency and output power $(90 \mathrm{~mW})$ in comparison with the green prototype $(165 \mathrm{~mW})$ due to partial plastic stress relaxation in the CdSe QD plane when its thickness exceeds the critical one $(\approx 3 \mathrm{ML}[4])$. An alternative way we proposed several years ago is to embed CdSe QDs into a strained $\mathrm{Zn}_{1-x} \mathrm{Cd}_{x}$ Se QW, which resulted in the emission wavelength of $565 \mathrm{~nm}$ [5].

This paper presents detailed theoretical calculations of the luminescence wavelength in the $\mathrm{CdSe} / \mathrm{Zn}_{1-x} \mathrm{Cd}_{x} \mathrm{Se} / \mathrm{Zn}(\mathrm{S}, \mathrm{Se})$ QD system $(x=0.3-0.5$, $\left.t_{\mathrm{CdSe}}=2.8-3.0 \mathrm{ML}\right)$ using the envelope-function approximation as well as experimental realization of QD-QW heterostructures emitting in yellow spectral range (570-600 $\mathrm{nm})$ by molecular beam epitaxy (MBE). The important element of the $\mathrm{CdSe} / \mathrm{Zn}_{1-x} \mathrm{Cd}_{x} \mathrm{Se} / \mathrm{Zn}(\mathrm{S}, \mathrm{Se})$ QD structure design is tensile strained $\mathrm{ZnS}_{y} \mathrm{Se}_{1-y} / \mathrm{ZnSe}$ superlattices (SLs) used for compensation of additional compressive strains induced by $\mathrm{Zn}_{1-x} \mathrm{Cd}_{x}$ Se QW. The choice of the SLs with different average lattice-mismatch to GaAs depending on parameters of the QD active region is justified.

\section{Experiment}

A series of test $\mathrm{CdSe}-\mathrm{QD} / \mathrm{Zn}_{1-x} \mathrm{Cd}_{x} \mathrm{Se}-\mathrm{QW}$ heterostructures were grown by $\mathrm{MBE}$ at $T_{\mathrm{S}}=270-280^{\circ} \mathrm{C}$ pseudomorphically on GaAs (001) substrates via GaAs buffer layer using a double chamber MBE setup (SemiTEq, Russia) [6]. Elemental Cd, Zn, and compound $\mathrm{ZnS}$ effusion cells, as well as a valved cracker Se cell (Veeco) were employed for growth. Figure 1 presents a deformation profile $(\Delta a / a)$ relatively to a GaAs lattice constant (Fig. 1a) along with the schematic band diagram (Fig. 1b) of a typical structure. The structure consisted of $0.1 \mu \mathrm{m}$ thick bottom $\mathrm{ZnS}_{0.17} \mathrm{Se}_{0.83} / \mathrm{ZnSe} \mathrm{SL}$ lattice-matched to GaAs (001) substrate with barrier-towell width ratio equal to $3 \mathrm{ML} / 5 \mathrm{ML}$, top and bottom $\mathrm{ZnS}_{0.17} \mathrm{Se}_{0.83} / \mathrm{ZnSe}$ compensation SLs with the thicknesses about $20 \mathrm{~nm}$ and $40 \mathrm{~nm}$, respectively, and an active region comprising $\mathrm{CdSe} \mathrm{QD}$ with the nominal thickness of $\approx 2.8 \mathrm{ML}$ placed in the middle of $\mathrm{Zn}_{1-x} \mathrm{Cd}_{x} \mathrm{Se}$ $\mathrm{QW}$. The $\mathrm{Zn}_{1-x} \mathrm{Cd}_{x}$ Se QW width as well as $\mathrm{Cd}$ content were varied within the $t_{\mathrm{QW}}=d_{1}+d_{2}=2 d_{1}=2 \div 5 \mathrm{~nm}$ (see Fig. 1) and $x=0.3 \div 0.5$ ranges. The $\mathrm{Cd}$ content 
in the $\mathrm{ZnCdSe} \mathrm{QW}$ were estimated as $x=\left(v_{\mathrm{ZnCdSe}}-\right.$ $\left.v_{\mathrm{ZnSe}}\right) / v_{\mathrm{ZnCdSe}}$, where $v_{\mathrm{ZnCdSe}}$ and $v_{\mathrm{ZnSe}}$ are the $\mathrm{ZnCdSe}$ and $\mathrm{ZnSe}$ growth rates measured by using reflection high energy electron diffraction (RHEED) oscillations technique at the initial stage of the II-VI heteroepitaxy under the Se-rich conditions. The parameters of the heterostructures grown are summarized in Table along with photoluminescence (PL) data. In addition, the gradedindex waveguide (GIW) laser heterostructure with the $2.8 \mathrm{ML}-\mathrm{CdSe} / \mathrm{Zn}_{0.65} \mathrm{Cd}_{0.35} \mathrm{Se} / \mathrm{ZnSe} \mathrm{QD}-\mathrm{QW}$ active region has been grown. The general design as well as the peculiarities of MBE growth of GIW laser heterostructures have been described in detail in Refs. [6, 7].

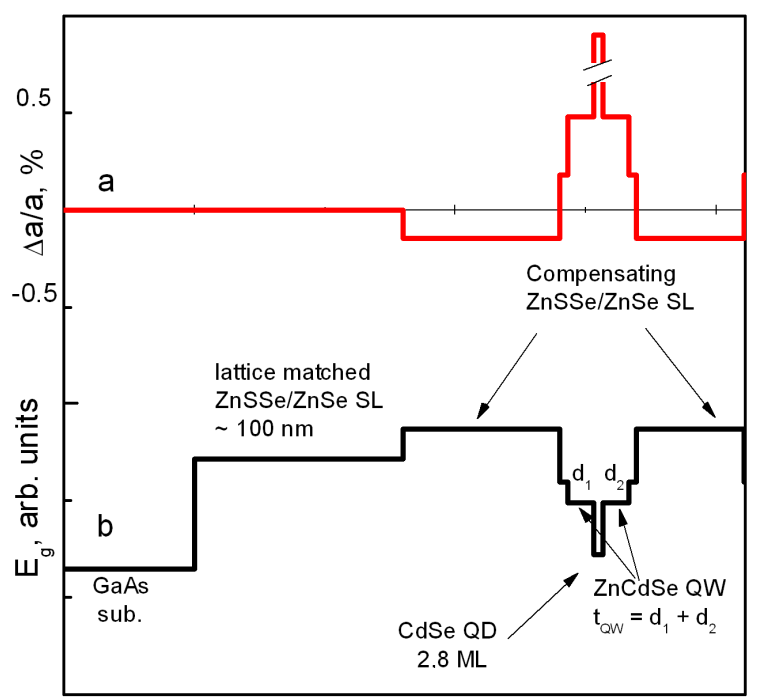

Fig. 1. Deformation profile $\Delta a / a$ along the growth direction of a CdSe/ZnCdSe QD-QW structure relative to the GaAs lattice constant (a) with corresponding schematic band diagram (b).

TABLE I

Parameters of grown heterostructures with the $\mathrm{CdSe} / \mathrm{Zn}_{1-x} \mathrm{Cd}_{x}$ Se QD-QW active region.

\begin{tabular}{c|c|c|c|c}
\hline \hline Sample & $\begin{array}{c}E_{\mathrm{PL}}[\mathrm{eV}] \\
(300 \mathrm{~K})\end{array}$ & $\begin{array}{c}E_{\mathrm{PL}}[\mathrm{eV}] \\
(77 \mathrm{~K})\end{array}$ & $\begin{array}{c}x \text { in } \\
\mathrm{Zn}_{1-x} \mathrm{Cd}_{x} \mathrm{Se} \mathrm{QW}\end{array}$ & $\begin{array}{c}\text { ZnCdSe QW } \\
\text { width [nm] }\end{array}$ \\
\hline $\mathrm{A}$ & 2.134 & 2.183 & 0.37 & 2 \\
$\mathrm{~B}$ & 2.065 & 2.116 & 0.44 & 3 \\
$\mathrm{C}$ & 2.097 & 2.144 & 0.42 & 3 \\
$\mathrm{D}$ & 2.169 & 2.220 & 0.35 & 3 \\
$\mathrm{E}$ & 2.139 & 2.187 & 0.38 & 3 \\
$\mathrm{~F}$ & 2.052 & 2.105 & 0.44 & 4
\end{tabular}

The PL spectroscopy at low $(77 \mathrm{~K})$ and room (RT) temperatures was used for the optical characterization of the heterostructures (Cube, Coherent Inc, $\lambda_{\text {exc }}=$ $404 \mathrm{~nm}$ ). The density of the extended defects in laser heterostructure has been estimated by means of etched pit density (EPD) technique [8].

\section{Theoretical calculations}

To determine luminescence wavelengths which can be achieved in CdSe QDs embedded in the $\mathrm{Zn}_{1-x} \mathrm{Cd}_{x} \mathrm{Se}$ QW as well as to estimate the range of the structure parameters ( $x$ and $t_{\mathrm{QW}}$ ) theoretical calculations were carried out, using one-dimensional envelope function approximation with materials parameters taken from [9]. The following assumptions were employed: CdSe QDs were considered as a $\mathrm{Zn}_{1-x} \mathrm{Cd}_{x}$ Se QW of Gaussian profile with $x=0.85-0.95$ at maximum (QW bottom) and the broadening parameter was chosen within 5-7 MLs in analogy with CdSe QDs in ZnSe matrix, studied accurately by using $\mathrm{X}$-ray diffraction [10] and transmission electron microscopy [11]. $\mathrm{Zn}_{1-x} \mathrm{Cd}_{x} \mathrm{Se} / \mathrm{ZnSe}$ band offsets were determined based on a model-solid theory [12], taking account of $\approx 40 \%$ elastic stress accommodation that occurs during CdSe QDs formation [13]. Results of the luminescence wavelength calculation at $300 \mathrm{~K}$ as a function of the surrounding $\mathrm{ZnCdSe} \mathrm{QW}$ width $\left(t_{\mathrm{QW}}\right)$ for the QD broadening parameter of 5 and $7 \mathrm{ML}$ are presented in Fig. 2 along with the experimentally obtained data (Table). The calculated dependences predict rather narrow range of the $\mathrm{Zn}_{1-x} \mathrm{Cd}_{x}$ Se QW thickness suitable to obtain yellow emission $\left(t_{\mathrm{QW}}=2.5-4 \mathrm{~nm}\right)$. The thicker $\mathrm{Zn}_{1-x} \mathrm{Cd}_{x}$ Se QW has been found to have no significant effect on emission wavelength but increases strongly the total compressive stress in the QD-QW system, whereas at $t_{\mathrm{QW}}$ below $2.5 \mathrm{~nm}$ the emission wavelength steeply decreases regardless of the $\mathrm{Cd}$ content in the $\mathrm{Zn}_{1-x} \mathrm{Cd}_{x}$ Se QW.

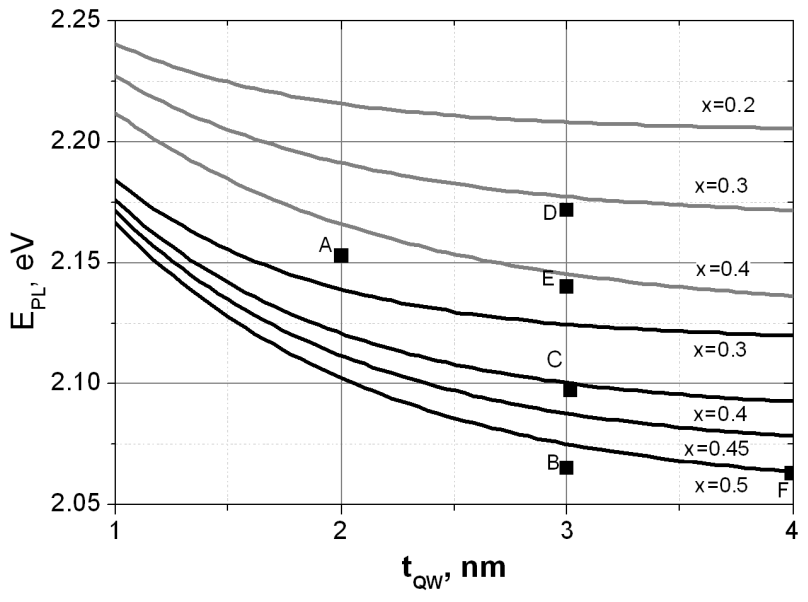

Fig. 2. Calculated luminescence wavelength at $300 \mathrm{~K}$ with broadening parameter of 5 ML (grey lines) and $7 \mathrm{ML}$ (black lines) as a function of the total $\mathrm{Zn}_{1-x} \mathrm{Cd}_{x}$ Se QW width at different $x$.

To avoid stress relaxation and defect formation in the complex ZnCdSe-QW/CdSe-QD system, taking into account that CdSe QDs with the nominal thickness below the critical one (3 ML) can be formed in a $\mathrm{ZnSe}$ matrix without plastic stress relaxation, we employed the surrounding tensile-strained $\mathrm{ZnS}_{0.17} \mathrm{Se}_{0.83} / \mathrm{ZnSe} \mathrm{SLs}$ 
for compensation of the compressive stress induced by the $\mathrm{Zn}_{1-x} \mathrm{Cd}_{x}$ Se QW. Figure 3 presents the calculated average SL lattice-mismatch to GaAs substrate for a set of $\mathrm{ZnS}_{0.17} \mathrm{Se}_{0.83} / \mathrm{ZnSe}$ SLs which can be used for the $\mathrm{Zn}_{1-x} \mathrm{Cd}_{x} \mathrm{Se} \mathrm{QW}$ stress compensation. In zero approximation, the compensating SLs can be chosen using a simple equation neglecting the difference in a shear modulus

$$
f_{\mathrm{QW}} t_{\mathrm{QW}}+f_{\mathrm{SL}} t_{\mathrm{SL}}=0,
$$

where $f_{\mathrm{QW}}$ and $t_{\mathrm{QW}}$ are the lattice mismatch to GaAs and the total width of $\mathrm{Zn}_{1-x} \mathrm{Cd}_{x} \mathrm{Se} \mathrm{QW}, f_{\mathrm{SL}}$ and $t_{\mathrm{SL}}$ are the average lattice mismatch to GaAs and the total thickness of $\mathrm{ZnS}_{y} \mathrm{Se}_{1-y} / \mathrm{ZnSe}$ SL. Grey region in Fig. 3 corresponds to the range of $t_{\mathrm{SL}}$ where it exceeds the critical thicknesses $\left(h_{\text {crit }}\right)$ of plastic relaxation for a certain $f_{\mathrm{SL}}$. This region was defined from a Cohen-Solal model for II-VI compounds [14] fitted to the experimental point $h_{\text {crit }}=150 \mathrm{~nm}$ of critical thickness for the ZnSe on GaAs $\left(f_{\mathrm{ZnSe}}=0.28 \%\right)[15]$.

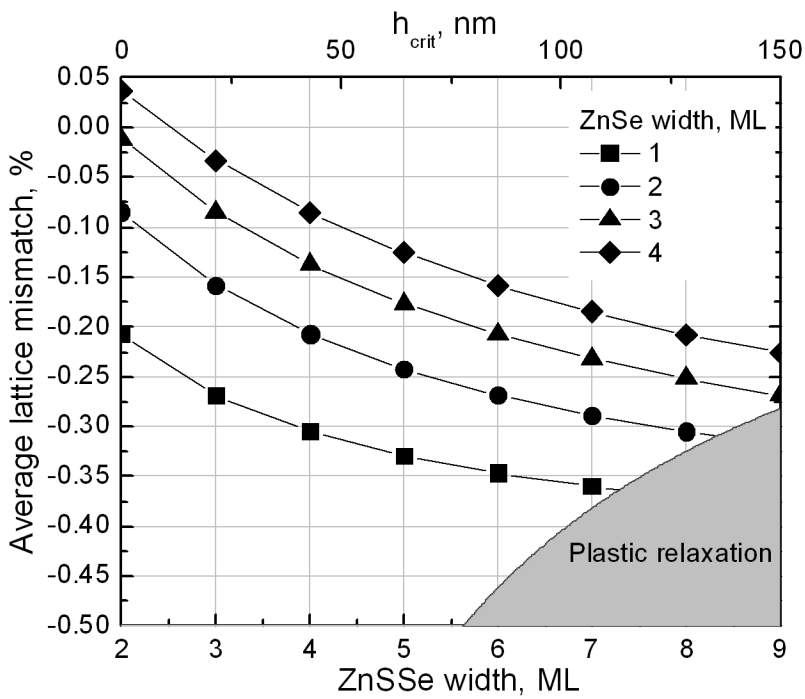

Fig. 3. Average lattice-mismatch to GaAs of $\mathrm{ZnS}_{0.17} \mathrm{Se}_{0.83} / \mathrm{ZnSe}$ SLs versus a SL barrier width at different SL well widths. The plastic relaxation region corresponds to the upper axis of the critical thickness of the $\mathrm{ZnSSe} / \mathrm{ZnSe} \mathrm{SL}$ versus its average lattice mismatch (left axis).

\section{Results and discussion}

It is clearly seen from Fig. 2 that calculated dependencies of the emission wavelength versus QD-QW structure parameters are in reasonably good agreement with the experimental results, which confirms the applicability of the proposed calculation model. But one should note that the experimental points with higher $\mathrm{Cd}$ content $(x>0.4)$ in the QW better correspond to the calculated curves with the QD broadening parameter equal to $7 \mathrm{ML}$. This can be explained by a Cd segregation effect which is more efficient when the surrounding $\mathrm{Zn}_{1-x} \mathrm{Cd}_{x}$ Se QW contains more $\mathrm{Cd}$, making the boundary between the QD and QW less pronounced. However this assumption needs in experimental verification using e.g. transmission electron microscopy measurements.

PL spectra of structure B at 300 and $77 \mathrm{~K}$ are presented in Fig. 4, with the maximum achieved QD luminescence wavelengths being as long as $600 \mathrm{~nm}$ and $586 \mathrm{~nm}$, respectively. However its RT peak intensity is still rather weak - 400 times lower than that at $77 \mathrm{~K}$, that presumably result from partial stress relaxation in $\mathrm{Zn}_{1-x} \mathrm{Cd}_{x}$ Se $\mathrm{QW}$ with the highest $\mathrm{Cd}$ content due to not complete stress compensation by the surrounding $\mathrm{ZnS}_{y} \mathrm{Se}_{1-y} / \mathrm{ZnSe} \mathrm{SL}$. Nevertheless, the shorterwavelength test structures demonstrated intense RT QD luminescence up to $\lambda=590 \mathrm{~nm}$.

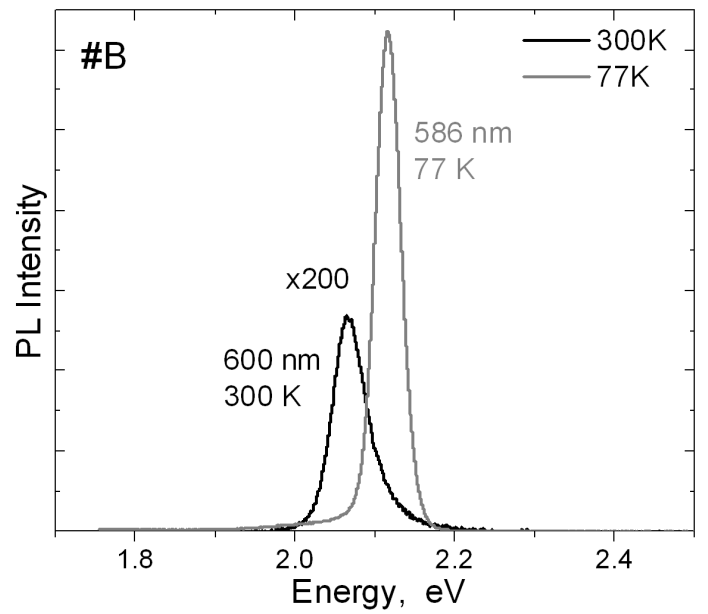

Fig. 4. PL spectra at 77 and $300 \mathrm{~K}$ of structure $\mathrm{B}$ with maximum achieved room temperature wavelength.

Based on both theoretical estimations and experimental findings, the 2.8 ML CdSe QDs/ $\mathrm{Zn}_{0.65} \mathrm{Cd}_{0.35} \mathrm{Se} \mathrm{QW}$ $\left(t_{\mathrm{QW}}=5 \mathrm{~nm}\right) / \mathrm{ZnSe}$ active region was introduced into the GIW laser heterostructure of optimal design [6]. The PL spectra at $T=77$ and $300 \mathrm{~K}$ of the GIW laser heterostructure are presented in Fig. 5. The QD PL peak at $2.152 \mathrm{eV}(576 \mathrm{~nm}, 300 \mathrm{~K})$ dominates strongly in the PL spectra and exceeds the SL peaks in intensity, which confirms the efficient carrier transport into the GIW SLs to the active region. The integral PL intensity of the QD-QW peak at RT is only about 2.6 times lower than that at $77 \mathrm{~K}$, indicating rather high internal quantum efficiency of the structure even at low excitation power. The density of the extended defects measured using EPD technique in this structure was as low as $<10^{5} \mathrm{~cm}^{-2}$.

As the following steps in increasing the RT PL efficiency of the CdSe-QD/ZnCdSe-QW heterostructures in the 590-600 nm range, one can propose (i) more accurate stress compensation by the $\mathrm{ZnS}_{y} \mathrm{Se}_{1-y} / \mathrm{ZnSe} \mathrm{SL}$ as well as (ii) employing of an asymmetrical active region where the CdSe QDs are deposited on a "pure" ZnSe surface and then overgrown by the $\mathrm{Zn}_{1-x} \mathrm{Cd}_{x} \mathrm{Se} \mathrm{QW}$ with the same 


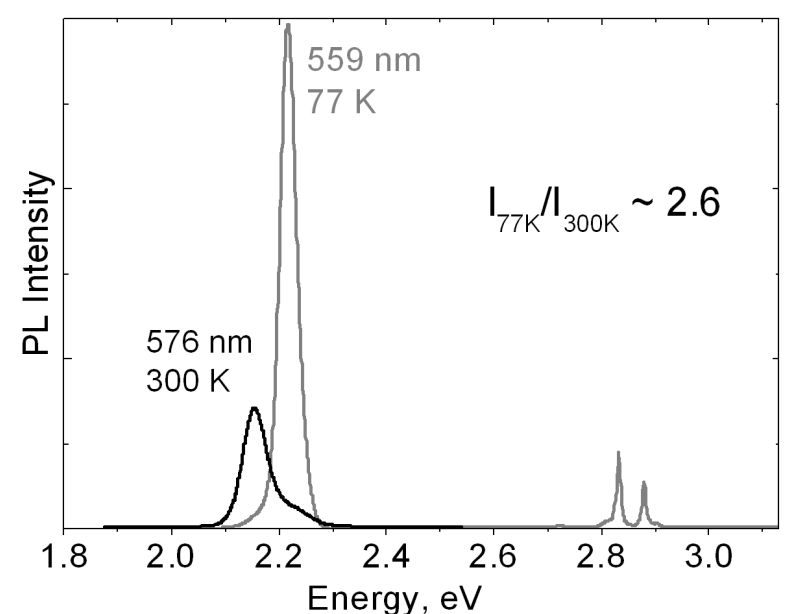

Fig. 5. PL spectra at 77 and $300 \mathrm{~K}$ of the II-VI GIW laser heterostructure with the active region comprising the $2.8 \mathrm{ML}$ CdSe QD plane in the $5 \mathrm{~nm}$ thick $\mathrm{Zn}_{0.65} \mathrm{Cd}_{0.35} \mathrm{Se} \mathrm{QW}$.

total width $t_{\mathrm{QW}}$. Indeed, deposition of the QD layer on the $\mathrm{Zn}_{1-x} \mathrm{Cd}_{x}$ Se surface possessing the $\mathrm{Cd}$ content fluctuations which cause corresponding fluctuations of the local strains could result in nucleation of much more inhomogeneous array of CdSe QDs with wider variation of QD size and Cd content. In this case the larger QDs with greater localization potential have higher probability of stress relaxation which makes them optically inactive and thus reduces the total PL efficiency of the structure. The more uniform QD nucleation surface (ZnSe) may enhance the density of large CdSe QDs with the size and composition below the critical ones. However in that case the $\mathrm{Cd}$ segregation on nucleated QDs during the $\mathrm{Zn}_{1-x} \mathrm{Cd}_{x} \mathrm{Se}$ overgrowth should be established precisely.

\section{Conclusions}

The calculations of the luminescence wavelength of the CdSe-QD $/ \mathrm{Zn}_{1-x} \mathrm{Cd}_{x} \mathrm{Se}-\mathrm{QW} / \mathrm{ZnS}_{y} \mathrm{Se}_{1-y}$ system pseudomorphic to GaAs have been performed by using the envelope-function approximation, which determine a rather narrow range of the total $\mathrm{Zn}_{1-x} \mathrm{Cd}_{x} \mathrm{Se} \mathrm{QW}$ thicknesses $\left(t_{\mathrm{QW}} \approx 2-4 \mathrm{~nm}\right)$ suitable to obtain the yellow emission at the CdSe QD nominal thickness of $\approx 2.8$ monolayer. Variation of $x(x=0.3-0.5)$ at constant $t_{\mathrm{QW}}=3 \mathrm{~nm}$ is more advantageous due to its strong effect on the emission wavelength, but it should be controlled precisely during MBE growth because of the possible negative effect of the Cd fluctuations on CdSe QD formation process. The applicability of the proposed model was confirmed by good agreement with experimentally obtained luminescence wavelengths in MBE grown CdSe$\mathrm{QD} / \mathrm{ZnCdSe}-\mathrm{QW} / \mathrm{ZnS}_{y} \mathrm{Se}_{1-y}$ heterostructures. To prevent the structures from relaxation the tensile-strained surrounding $\mathrm{ZnS}_{y} \mathrm{Se}_{1-y} / \mathrm{ZnSe}$ superlattices were introduced to compensate the compressive stress induced by the $\mathrm{Zn}_{1-x} \mathrm{Cd}_{x} \mathrm{Se} \mathrm{QW}$. The maximum achieved emission wavelength at $300 \mathrm{~K}$ is as high as $600 \mathrm{~nm}$, whereas the intense PL is observed up to $\lambda=590 \mathrm{~nm}$ only. The high quantum efficiency laser heterostructure emitting at $\lambda=576 \mathrm{~nm}(300 \mathrm{~K})$ with the extended defect density below $10^{5} \mathrm{~cm}^{-2}$ has been realized on the basis of theoretical and experimental findings for applications in II-VI/III-N laser diode converters.

\section{Acknowledgments}

The work has been done at the partial support by RFBR grant \#14-02-01226.

\section{References}

[1] M. Klude, D. Hommel, Appl. Phys. Lett. 79, 2523 (2001).

[2] J.-I. Kasai, R. Akimoto, T. Hasama, H. Ishikawa, S. Fujisaki, S. Tanaka, S. Tsuji, Appl. Phys. Expr. 4, 082102 (2011).

[3] E.V. Lutsenko, M.V. Rzheutski, G.P. Yablonskii, S.V. Sorokin, S.V. Gronin, I.V. Sedova, P.S. Kop'ev, S.V. Ivanov, M. Alanzi, A. Hamidalddin, A. Alyamani, Quantum Electron. 43, 418 (2013).

[4] S.V. Ivanov, A.A. Toropov, S.V. Sorokin, T.V. Shubina, I.V. Sedova, A.A. Sitnikova, P.S. Kop'ev, Zh.I. Alferov, H.-J. Lugauer, G. Reuscher, M. Keim, F. Fischer, A. Waag, G. Landwehr, Appl. Phys. Lett. 74, 498 (1999).

[5] I.V. Sedova, O.G. Lyublinskaya, S.V. Sorokin, S.V. Gronin, A.A. Sitnikova, S.V. Ivanov, J. Korean Phys. Soc. 53, 3012 (2008).

[6] S.V. Gronin, I.V. Sedova, S.V. Sorokin, G.V. Klimko, K.G. Belyaev, A.V. Lebedev, A.A. Sitnikova, A.A. Toropov, S.V. Ivanov, Phys. Status Solidi C 9, 1833 (2012).

[7] I.V. Sedova, E.V. Lutsenko, S.V. Gronin, S.V. Sorokin, A.G. Vainilovich, A.A. Sitnikova, G.P. Yablonskii, A. Alyamani, D.L. Fedorov, P.S. Kop'ev, S.V. Ivanov, Appl. Phys. Lett. 98, 171103 (2011).

[8] M. Shiraishi, S. Tomiya, S. Taniguchi, K. Nakano, A. Ishibashi, M. Ikeda, Phys. Status Solidi A 152, 377 (1995).

[9] Handbook on Physical Properties of Semiconductors, Vol. 3, II-VI Compound Semiconductors, Springer, 2004.

[10] R.N. Kyutt, A.A. Toropov, S.V. Sorokin, T.V. Shubina, S.V. Ivanov, M. Karlsteen, M. Willander, Appl. Phys. Lett. 75, 373 (1999).

[11] N. Peranio, A. Rosenauer, D. Gerthsen, S.V. Sorokin, I.V. Sedova, S.V. Ivanov, Phys. Rev. B 61, 16015 (2000).

[12] C.G. Van de Walle, Phys. Rev. B 39, 1871 (1989).

[13] F. Tinjod, I.-C. Robin, R. Andre, K. Kheng, H. Mariette, J. Alloys Comp. 371, 63 (2004).

[14] G. Cohen-Solal, F. Bailly, M. Barbé, J. Cryst. Growth 138, 68 (1994).

[15] A. Benkert, C. Schumacher, K. Brunner, R.B. Neder, Appl. Phys. Lett. 90, 162105 (2007). 